\title{
A polymath's dilemma
}

\section{Thomas Young strove to satisfy his curiosity in virtually every scientific subject and, undeterred by sceptics calling for a narrower focus, made discoveries in almost all the fields he studied.}

\section{Andrew Robinson}

Polymaths have always posed a problem in academia. How do they relate to specialization and interdisciplinarity, genius and dilettantism, inspiration and perspiration? Robert Hooke, Benjamin Franklin and Alexander von Humboldt were among those who were too academically wide-ranging for posterity to cope with, and their scientific reputations suffered as a consequence.

Individual curiosity is the driving force of science, but when insatiable, can it hamper the intellectual? The life and work of the polymath Thomas Young (1773-1829) illuminates the issue perhaps more acutely than that of any other scientist. Today, views of Young span the spectrum from near-universal genius to dabbling dilettante. Those who appreciate him - especially physicists, physiologists and Egyptologists - admire his range, his intuition and his farsightedness. Those who do not, depreciate these same aspects of his life and work as sloppiness and opportunism.

Some great names of nineteenth-century science, notably John Herschel, Hermann von Helmholtz and John William Strutt (Rayleigh), were in awe of Young. In 1931, Einstein paid tribute to him in a brief foreword to Newton's Opticks; he referred to Newton's observations of the colours of thin films "as the origin of the next great theoretical advance, which had to await, over a hundred years, the coming of Thomas Young." In Nature, Joseph Larmor, a former Lucasian professor of mathematics at Cambridge, wrote an essay on Young calling his 1802-03 lectures on natural philosophy at the Royal Institution "the greatest and most original of all general lecture courses". In 1973 , on Young's bicentenary, the Science Museum in London noted, startlingly, that "Young probably had a wider range of creative learning than any other Englishman in history. He made discoveries in nearly every field he studied."

Young made a pioneering contribution to the understanding of light by demonstrating interference patterns, known as 'Young's fringes, around 1800, which led to the Young-Fresnel undulatory theory. He also formulated an important measure of elasticity, called 'Young's modulus'. He was the first to explain the accommodation of the eye; he discovered the phenomenon of astigmatism; and he proposed the three-

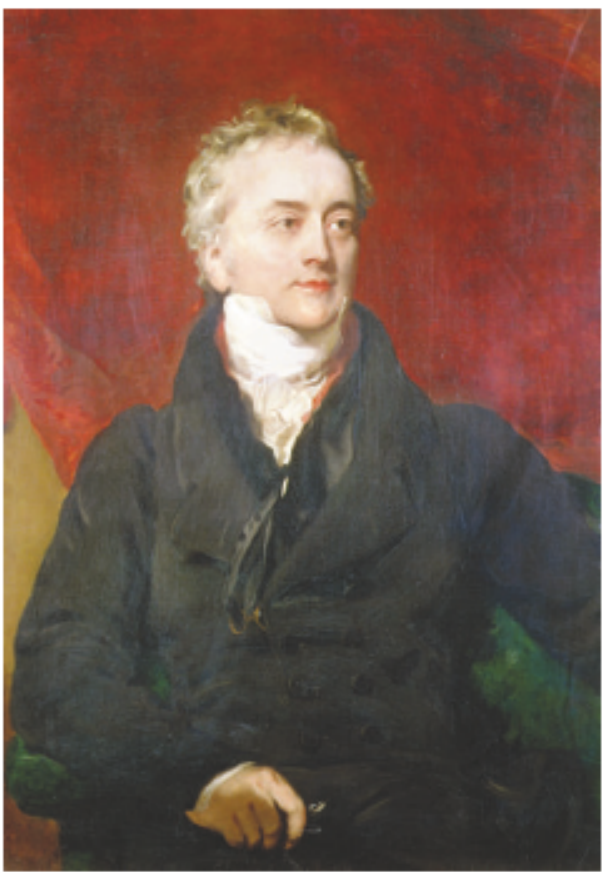

World explor er: from the human eye to Egyptian script, Thomas Young's interests ranged widely.

colour theory of vision. This was later known as the Young-Helmholtz theory, and was finally confirmed experimentally in 1959 . He undertook seminal detective work on the Rosetta Stone and helped to found Egyptology. Although the credit for finally reading the hieroglyphs belongs to Jean-François Champollion, Young was the decipherer of the second type of Egyptian script on the Rosetta Stone, known as demotic script.

In addition, he was a distinguished physician at St George's Hospital; foreign secretary of the Royal Society for a quarter of a century; an authoritative writer on all manner of subjects; a major scholar of ancient Greek; and a phenomenal linguist who coined the term 'Indo-European' for the language family that includes Greek and Sanskrit.

When pressed to contribute to the Encycopaedia Britannica, Young offered articles on the alphabet, annuities, attraction, capillary action, cohesion, colour, dew, Egypt, the eye, focus, friction, haloes, hieroglyphics, hydraulics, motion, resistance, ships, sound, strength, tides, waves and "anything of a medical nature. And he wasn't boasting: having been an 'inspector of calculations' and physician of a Londonbased life-insurance company in the $1820 \mathrm{~s}$, he knew about annuities. And his roles as adviser to the Admiralty on shipbuilding, secretary of the Board of Longitude, and superintendent of the vital Nautical Almanac from 1818 until his death had informed him on ships.

He also wrote many biographical articles about scientists and mathematicians, an occupation that led him to reflect on his own intellectual motivation to a close friend: ${ }^{\alpha}$ The biographical articles seldom amuse me much in writing; there is too little invention to occupy the mind sufficiently: I like a deep and difficult investigation when I happen to have made it easy to myself if not to all others - and there is a spirit of gambling in this, whether as by the cast of a die, a calculation à perte de vue, shall bring out a beautiful and simple result, or shall be wholly thrown away.

Scarcely the words of a dilettante. But, on the other hand, Young was restlessly curious. He generally moved on long before he had fully explored his intuitions and discoveries. As a result, his reputation suffered, which he well knew. "Whether the public would have been more benefited by his confining his exertions within narrower limits, is a question of great doubt," Young said in an autobiographical sketch intended for a posthumous edition of the Britannica. After his death, the president of the Royal Society could not help but echo this ambivalence towards polymathy in a valedictory address: ${ }^{\alpha}[\mathrm{His}]$ example is only to be followed by those of equal capacity and equal perseverance; and rather recommends the concentration of research within the limits of some defined portion of science, than the endeavour to embrace the whole."

Whether one admires polymaths seems a matter of taste, not objective judgement. But it should surely be indisputable that a man of sweeping vision like Young has a place in science as valuable as, say, the more narrowly focused Augustin Fresnel, Helmholtz or Champollion. In Young's own perceptive words: ${ }^{\alpha} \mathrm{It}$ is probably best for mankind that the researches of some investigators should be conceived within a narrow compass, while others pass more rapidly through a more extensive sphere of research."

Andrew Robinson is the author of a biography of Thomas Young, The Last Man Who Knew Everything, which is to be published by Pi Press in January. He is literary editor of The Times Higher Education Supplement. 